\title{
Diagnosis of Machines in the Forestry Systems
}

\author{
Svetozar Madzhov \\ Forest Research Institute, Bulgarian Academy of Sciences, Sofia 1756, Bulgaria
}

\begin{abstract}
This article discusses the possibilities of increasing the efficiency of TM (Technical Maintenance) and R (Repair) of machines by means of technical diagnostics. Characteristics of the diagnostic signs and parameters are formulated. A classification of diagnostic parameters is proposed.
\end{abstract}

Key words: Technical diagnostics, diagnostic features, diagnostic parameters.

\section{Introduction}

The increasing of efficiency of TM (Technical Maintenance) and R (Repair) of machinery (tractors, cars and other machinery) requires individual information on their technical condition up, until and after their servicing and repair.

It is necessary that the received information is accessible without taking apart of their mechanisms and aggregates and without investing large labor costs upon its delivery. The individual information on hidden and potential failures allows preventing premature or delayed repair and prevention, and thus also controlling the quality of the performed repairs [1,2].

\section{Materials and Methods}

A means of obtaining such information is the machines technical diagnostics.

Technical condition is a complexity of site properties subject to change in the production or operation process, characterized at some point in time by the features established in the technical documentation of the site and (or) parameters of the state established in the technical documentation of that site [2].

Conditions of use is a set of natural climatic, production-economic, organizational-technical and socio-economic factors acting on the site in use.

Corresponding author: Svetozar Madzhov, Ph.D., assistant professor, main research field: forest mechanization and reliability.
Technical diagnostics is called a knowledge branch learning the signs of machine failure, methods, tools and algorithms to determine their technical condition without disassembly, as well as the technology and organization of using the diagnostic system in the process of technological use of machines.

Diagnosis is a process of determining the technical condition of the objects without disassembly, by external signs by measuring parameters characterizing its state and comparing them with the normative. Diagnosis provides the system of $\mathrm{TM}$ and $\mathrm{R}$ of machines with individual information about their technical condition and is therefore an element of this system. The diagnosis of an object is performed according to an algorithm (set of consecutive actions) set out in the technical documentation. The complex, which includes the object, means and algorithms, constitutes the diagnostic system [3, 4].

The diagnostic system object is characterized by the necessity and the possibility of diagnosis. The need for diagnosis is determined by the laws of changing its technical condition and the costs of maintaining its working capacity. The possibilities for diagnosis are determined by the presence of external signs, which allow determining of machine failure without disassembly, as well as accessibility to measure these signs.

The diagnostic devices are special instruments and stands. They are external (separate) and built in, which are component parts of the machine. Diagnosis is used 
not only for measuring technical devices, but also for the subjective abilities of the person, his sensitive organs, experience, habits; whereas subjective diagnosis is used in simple cases, and in complex-objective diagnosis.

Diagnostic systems (Fig. 1) are divided into functional systems - when the diagnosis is performed during the object's operation and test system - when the performance of the object is reproduced artificially when measuring the diagnostic parameters. Authors differentiate a universal diagnostic system-designed for several different diagnosis processes, and a special system - providing only one diagnostic process.

Diagnostic systems may be general-when the subject is an integral product and the purpose is to determine its status at the "fit-for-use" level and local systems-for diagnosis of components (systems, aggregates, nodes). Furthermore, the diagnostic tools can be collected manually or automatically.

Forecasting the technical condition of the machines means to define the duration of their work to their limit, according to the technical documentation
(Bulgarian National Standard, Industry Norms, Factory Instructions). An assessment of the technical state of the site in the past (for example, to reveal the reasons for an emergency denial that caused a road accident) is called retrospection (Fig. 2). The practical tasks of forecasting or retrospection are solved by the means of using renowned regulations of the parameters changes of the technical condition of the object in function of the work on the extrapolation or interpolation path.

Diagnosis is periodic and continuous. The first one is performed during a certain period of work on the site prior to the machine's TM or R and the second one-by the built-in diagnostic tools in the machine during operation.

\section{Results and Discussion}

The ability to immediately measure the structural parameters (wear, slack) of machine mechanisms joints without disassembly during operation, is very limited. Therefore, indirect indications reflecting the technical condition of the machines are used. These

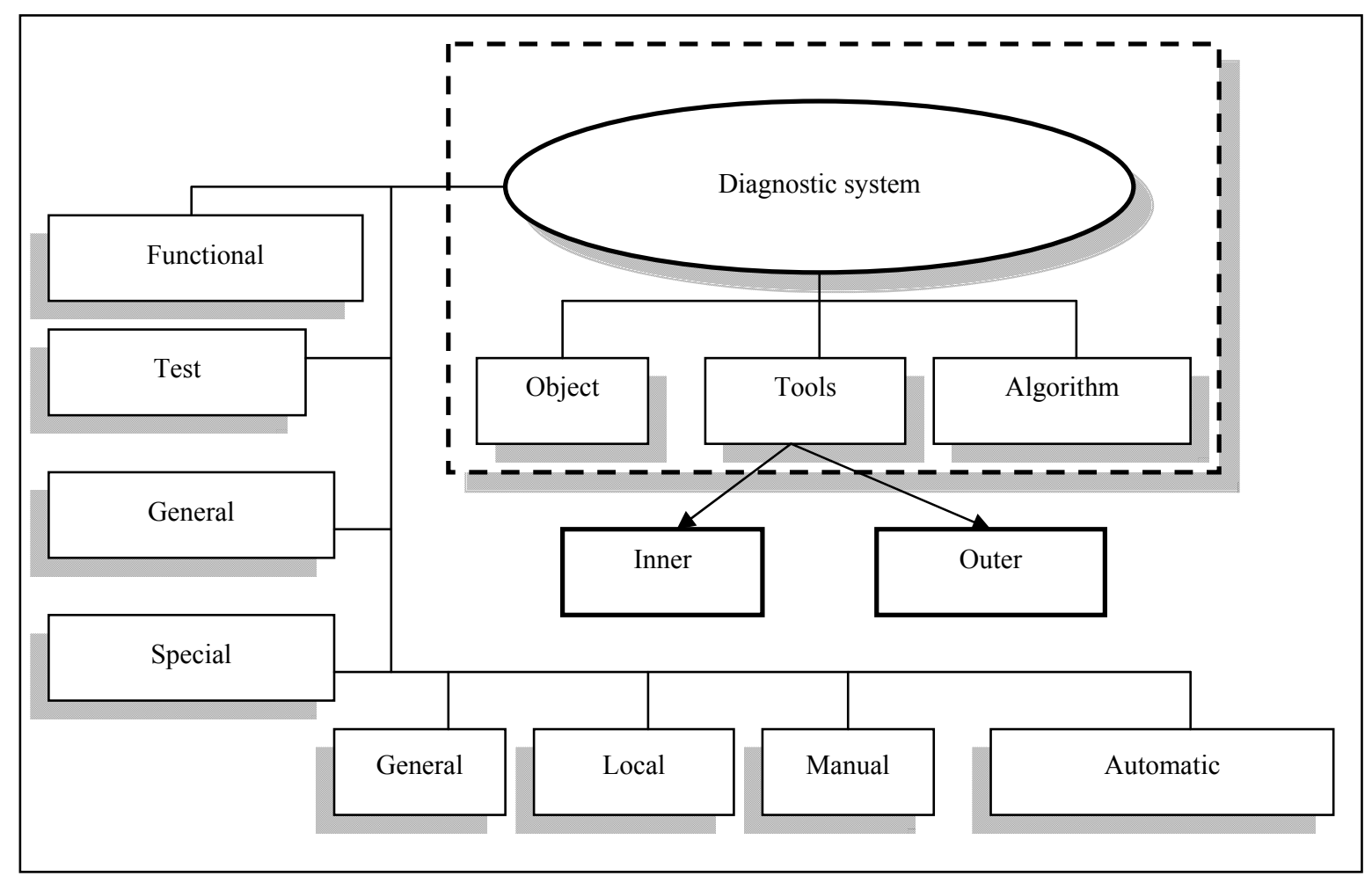

Fig. 1 Structural version of the diagnostic system. 


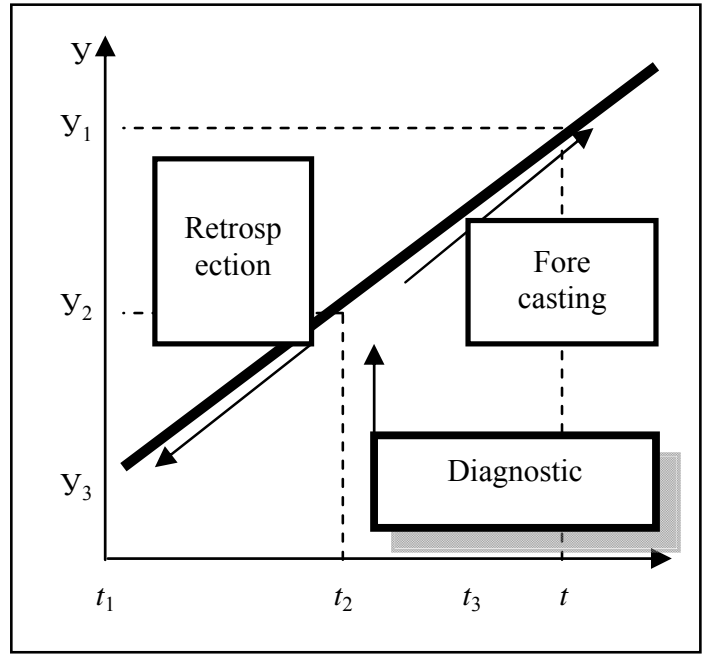

Fig. 2 Object's technical condition determination scheme. $\mathrm{y}_{1}$-value of the diagnosis parameter in the moment $t_{3}$ (prognosis);

$\mathrm{y}_{2}$ - the value of the diagnosis parameter in the moment of diagnostic $t_{2}$;

$\mathrm{y}_{3}$-value of the diagnosis parameter in the moment $t_{1}$ (retrospection).

indications are called diagnostic parameters and are suitable for measurement of physical dimensions related to the parameters of the technical condition of the machines and they provide information about their condition.

Parameter of technical condition is a physical dimension that characterizes the functionality of the element, gradually changes in the process of use and at any point in time reflects the level of operational capacity of the object.

Structural parameter of state is a parameter, which directly characterizes the performance of the element (wear, dimension of the parts, clearance, tightening in the joints).

Diagnostic parameter of the status is a parameter that indirectly or directly characterizes the element's interoperability (temperature, noise, vibrations, fuel consumption, oil, etc.) used in established order to determine the technical condition of the element.

Diagnostic parameters can be: parameters of work processes (power, braking path, fuel consumption, etc.), parameters, accompanying processes (vibrations, noise, etc.) and geometric dimensions (slack, free stroke, beating, looseness, etc. (Fig. 3) [3, 5-7].

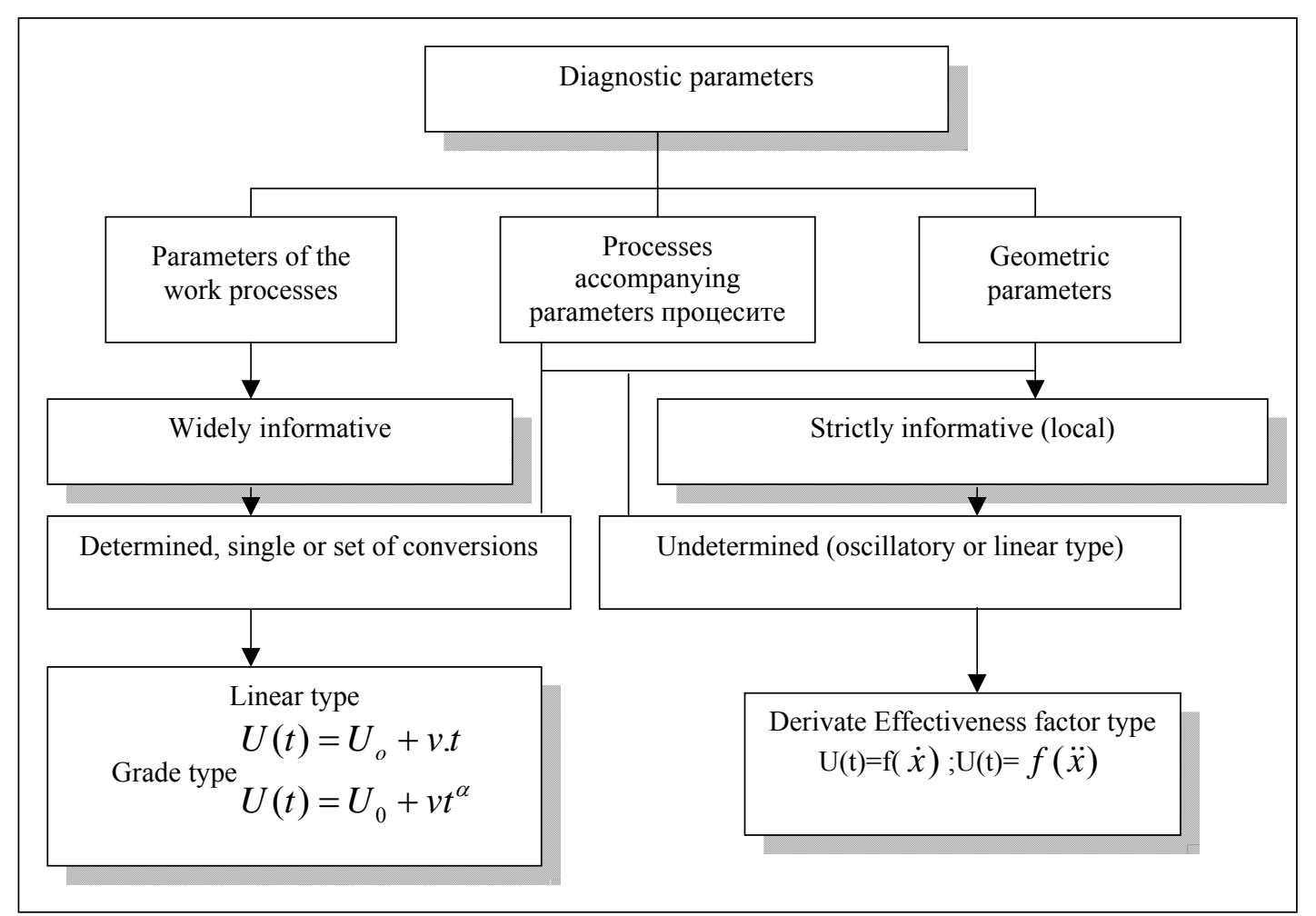

Fig. 3 Classification of diagnostic parameters: (a) in principle of formation; (b) by type of information; (c) by function of production; (d) by functions of structural parameters. 
Table 1 Diagnostic signs and parameters characteristics.

\begin{tabular}{|c|c|c|}
\hline Diagnostic features & Diagnostic parameters & Application scope \\
\hline $\begin{array}{l}\text { Fact operational or non-operational object } \\
\text { (on start-up, switching, test) }\end{array}$ & 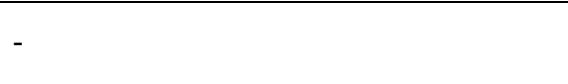 & $\begin{array}{l}\text { Lighting and signaling tools, engine, } \\
\text { traction and more. }\end{array}$ \\
\hline Decrease in efficiency & $\begin{array}{l}\text { Power, braking, performance, traction and } \\
\text { speed; decrease in the rotational speed of } \\
\text { the crankshaft of the engine at exclusion of } \\
\text { the cylinders }\end{array}$ & $\begin{array}{l}\text { Engine, brakes, rechargeable battery, } \\
\text { traction }\end{array}$ \\
\hline Correctness of geometric compounds & $\begin{array}{l}\text { Linear and angular gaps/ loops/, free and } \\
\text { working strokes }\end{array}$ & $\begin{array}{l}\text { Front axle, steering, drive mechanisms, } \\
\text { wheel bearings }\end{array}$ \\
\hline Correctness of cyclical processes & $\begin{array}{l}\text { Changing the amperage and voltage of the } \\
\text { electrical circuit; changing the fluctuations } \\
\text { of the undercoating tables; variation in } \\
\text { ignition setting, distortion between the } \\
\text { crankshaft speed and the camshaft }\end{array}$ & $\begin{array}{l}\text { Ignition system, generator, suspension, } \\
\text { traction }\end{array}$ \\
\hline Deviation from the acoustic process norms & $\begin{array}{l}\text { Vibro-impulses, frequency and phase of } \\
\text { oscillations, amplitude components of the } \\
\text { spectrum, noise level }\end{array}$ & $\begin{array}{l}\text { Engine, transmission aggregates, fuel } \\
\text { equipment }\end{array}$ \\
\hline Changes in cork oil composition & $\begin{array}{l}\text { Viscosity, cynicity, presence of water, } \\
\text { presence and concentration of wear products }\end{array}$ & Engine, lubrication system, cooling system \\
\hline Change of exhaust composition & $\mathrm{CO}, \mathrm{CO}_{2}$ and soot content & Engine, ignition system, fuel system \\
\hline The thermal state & Temperature and rate of change & $\begin{array}{l}\text { Cooling system, lubrication system, } \\
\text { transmission units, wheel bearings, traction }\end{array}$ \\
\hline $\begin{array}{l}\text { Change of Effectiveness factor of the } \\
\text { diagnostic object }\end{array}$ & $\begin{array}{l}\text { Acceleration, torque of the transmission, } \\
\text { torque control force, indicator diagram }\end{array}$ & $\begin{array}{l}\text { Transmission, steering, wheel bearings, } \\
\text { motor }\end{array}$ \\
\hline $\begin{array}{l}\text { Changing the type of the surface of the } \\
\text { object }\end{array}$ & $\begin{array}{l}\text { Visual monitoring of deformations, leaks, } \\
\text { cracks, wear of the wheels }\end{array}$ & $\begin{array}{l}\text { Engine, cabin, aggregates and systems, } \\
\text { tires, etc. }\end{array}$ \\
\hline
\end{tabular}

The physical characteristics of the diagnostic features, the diagnostic parameters and the area of their application in the diagnostics of machines are shown in Table 1.

The relationship between structural and diagnostic parameters is shown in Fig. 4. An example of the parameters of the piston cylinder group and the crankshaft mechanism are given in Table 2.

In order to be able to measure the structural parameter of the mechanism, the unit or the knot, it is necessary to know the direct and the inverse relation between structural and diagnostic parameters. The relationships between the structural and diagnostic parameters can be (Fig. 5): (a) single (for simple mechanisms), (b) multiple, (c) unspecified (with a given diagnostic parameter, several different failures are possible) and (d) composite.

Resource parameter of the technical condition is a parameter which changes over the limit value and leads to loss of functionality of the machine components due to the depletion of the resource, which is restored by repairing or replacing the element.

Parameter implementation is uninterrupted change of the parameter status of a particular diagnostic object. The regulations of changing of the diagnostic parameters in function of the machine's manufacturing are identical to the regulations of change of the parameter of its technical condition.

Functional parameter is a parameter, which changes over the limit value and leads to a loss of performance or failure that should be recovered during the TM.

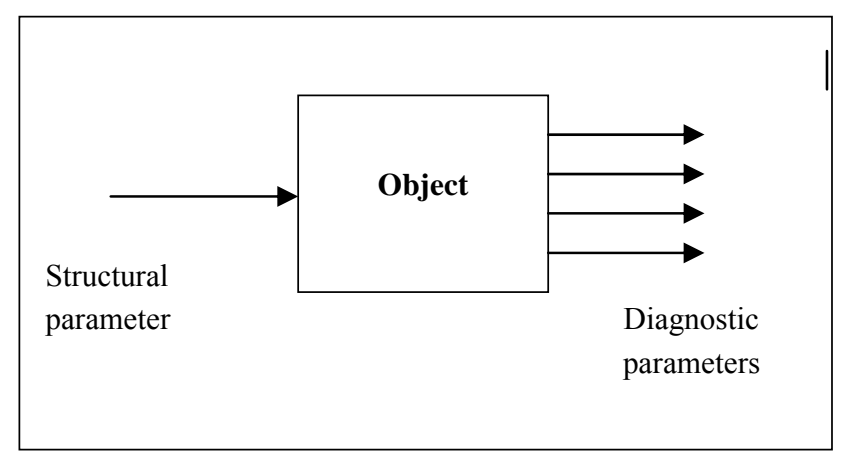

Fig. 4 Relationship between structural and diagnostic parameters. 
Table 2 Parameters of the piston cylinder group and the crankshaft mechanism.

\begin{tabular}{ll}
\hline Structural parameters & Diagnostic parameters \\
\hline Pump-cylinder wear & Oil consumption; gas leakage through the crankcase; vibroacoustic signals and more. \\
Wear of the crankshaft bearings and cranks & Oil pressure on the highway; vibroacoustic signals and more. \\
\hline
\end{tabular}

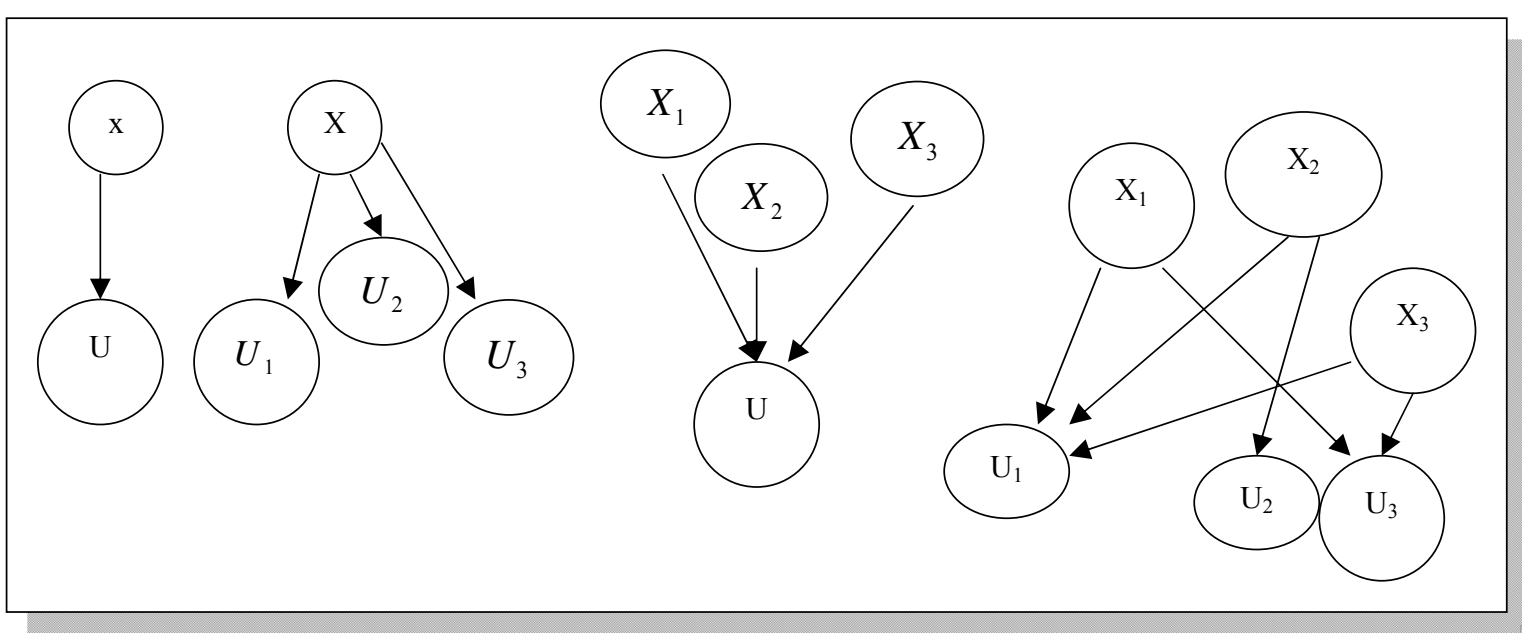

(a)

(b)

(c)

(d)

Fig. 5 Relationship between diagnostic and structural parameters.

Generalized parameter of the technical condition is diagnostic parameter, characterized by tolerable error in the technical condition of several machine parts.

\section{General Conclusions}

(1) The necessity of managing the technical condition of the machines through the methods and tools of the technical diagnostics has been motivated.

(2) The characteristics of the diagnostic indications and parameters have been introduced.

(3) A classification of the diagnostic parameters is proposed: according to the formation principle, by type of information; by function of manufacture, by functions.

\section{References}

[1] Ivanova, N., and Nikolov, M. 2015. "Optimizing the Parameters of the Inventory Management System for Normal Distribution of Spare Part Orders." In
Proceedings of the XXIV International Scientific Conference “Management and Quality 2015” for Young Scientists, Collection of Scientific Papers, 15-16, June, 2015, Varna, Bulgaria, pp. 157-65, ISSN1314-4669.

[2] Mihov, M. 2012. Reliability of Machinery in Agriculture. Sofia, Bulgaria.

[3] Teper, N. L., Ivanova, N., and Krastev, K. 2014. "Optimum Machine Durability." In Collection of Reports International Scientific Conference "Reliability and Risk of Processes and Machines”. Sofia, Bulgaria.

[4] Mihov, M., Georgieva, K., and Ivanova, N. 2017. "Modern Approaches to Quality Management of Agricultural Technology." In Proceedings of the 5th International Scientific Congress "Agricultural Machinery”, 21-24, June, 2017, Varna, Bulgaria, pp. 197-9, ISSN2535-0269.

[5] Mihov, M., Georgieva, K., and Ivanova, N. 2017. "Current Problems of Agricultural Production Mechanization." In Proceedings of the 5th International Scientific Congress “Agricultural Machinery”, 21-24, June, 2017, Varna, Bulgaria, pp. 205-8, ISSN2535-0269.

[6] Mihov, M., and Tasev, G. 2012. Maintenance and Repair of Machines. Sofia, Bulgaria. 